\title{
Comparative study on effects of injection mode on combustion and emission characteristics of a combined injection n-butanol/gasoline SI engine with hydrogen direct injection
}

\author{
Zhen Shang ${ }^{\text {a }}$, Xiumin Yu ${ }^{\mathrm{a}, *}$, Lei Ren ${ }^{\mathrm{b}}$, Guowu Wei ${ }^{\mathrm{c}}$, Guanting $\mathrm{Li}^{\mathrm{a}}$, Decheng Li ${ }^{\text {a }}$, Yinan $\mathrm{Li}^{\text {a }}$ \\ ${ }^{a}$ State Key Laboratory of Automotive Simulation and Control, Jilin University, Changchun, Jilin 130022, China \\ ${ }^{\mathrm{b}}$ School of Mechanical, Aerospace and Civil Engineering, University of Manchester, Manchester, M13 9PL, UK \\ ${ }^{c}$ School of Computing, Science and Engineering, University of Salford, Manchester, M5 4WT, UK
}

\begin{abstract}
In this paper, on the basis of combined injection technique, three injection modes with five n-butanol/gasoline volume ratios $\left(v_{N}\right)$ were put forward, aiming to compare and evaluate the relationship between the injection mode and the combustion and emission characteristics of an n-butanol/gasoline SI engine equipped with an extra hydrogen direct injection system. The results indicated that under low load condition, compared with NGP (n-butanol/gasoline port injection) mode, the $\mathrm{NG}_{\mathrm{PD}}$ (n-butanol/gasoline combined injection) mode and $\mathrm{NG}_{\mathrm{PH}}$ (n-butanol/gasoline with hydrogen combined injection) mode can both improve the combustion performance. The peak cylinder pressure of $\mathrm{NG}_{\mathrm{PD}}$ and $\mathrm{NG}_{\mathrm{PH}}$ mode was $5.58 \%$ and $11.63 \%$ higher than that of $\mathrm{NG}_{\mathrm{P}}$ mode on average, respectively. Furthermore, the combined injection modes concentrated the process of heat release, shortened the combustion duration, increased the power performance and improved the combustion stability at all $v_{N}$. As for emissions, the $\mathrm{NG}_{\mathrm{PD}}$ and $\mathrm{NG}_{\mathrm{PH}}$ combined modes significantly decreased the $\mathrm{HC}$ and $\mathrm{CO}$ emissions, but increased the $\mathrm{NO}_{\mathrm{x}}$ emissions. Among all the test conditions, the $\mathrm{NG}_{\mathrm{PH}}$ mode with $25 \% v_{N}$ obtained the best combustion quality. Additionally, the effect rules of $v_{N}$ on combustion and emission characteristics under $\mathrm{NG}_{\mathrm{P}}$ mode were found to be consistent with those under
\end{abstract}


$\mathrm{NG}_{\mathrm{PD}}$ and $\mathrm{NG}_{\mathrm{PH}}$ combined modes.

Keywords: N-butanol/gasoline blends; N-butanol volume ratio; Hydrogen direct injection; Combined injection; Combustion and emission

\section{Introduction}

The port fuel injection (PFI), which is regarded as the main conventional injection method of SI engines, is limited by the use of a throttle valve for load control and fuel delivery delay. To overcome these major problems associated with PFI, the gasoline direct injection (GDI) technology has been introduced [1,2]. Injecting fuel directly into the cylinder improves power performance and fuel efficiency, but requires high-pressure injector and increases $\mathrm{NO}_{\mathrm{X}}$ and PM emissions [3-5]. Thus, under the premise that automobiles will remain as the main transport system, finding high-efficiency and low-emission injection methods and appropriate alternative fuels are of great significance to improve the current problems of atmospheric pollution and reduce the dependence on petroleum [6,7].

As a biomass-based renewable fuel, n-butanol is considered to be among the most competitive alternative fuels for engines [8]. The favorable properties of n-butanol, including higher octane rating, laminar flame speed and

Abbreviations: SI, spark-ignition; PFI, port fuel injection; GDI, gasoline direct injection; HDI, hydrogen direct injection; $v_{N}, \mathrm{n}$-butanol volume ratio; MBT, minimum advance for best torque; CA, crank angle; BTDC, before top dead center; ATDC, after top dead center; TDC, top dead center; BMEP, brake mean effective pressure; COV, coefficient of variation; CO, carbon monoxide; HC, hydrocarbon; NOx, nitrogen oxide; PM, particulate matter.

*Corresponding author.

E-mail address: yuxm@jlu.edu.cn (X. Yu). 
oxygen content in comparison with gasoline are shown in Table 1. Additionally, due to the close physico-chemical similarities between n-butanol and gasoline, and the n-butanol intersolubility characteristics with gasoline in any proportion [9]; blending n-butanol into gasoline as a hybrid fuel can be easily integrated into the existing fuel distribution infrastructure and match the regular gasoline engine well without much complicated modification [10]. Significantly, n-butanol is superior to methanol and ethanol due to its higher heating value and viscosity, lower vaporization heat and auto-ignition temperature, which indicates that the n-butanol has potential to surmount the disadvantages of short-chain alcohols [11]. Thus, choosing n-butanol blending gasoline as alternative fuel instead of pure gasoline in SI engine is an effective and implementable way to relieve the dependency on fossil fuels, obtain favorable combustion characteristics and reduce exhaust emissions [12,13].

Since the study of applying n-butanol as engine fuel, there are two major hybrid approaches for n-butanol and gasoline, premixed or independent dual injection. Elfasakhany [14] concluded that using small blend rate of nbutanol ( below $10 \mathrm{vol} \%$ ) into gasoline significantly improved the $\mathrm{CO}$ and $\mathrm{HC}$ emissions with few drawbacks on burning behavior of an unmodified single-cylinder SI engine. Chen et al. $[15,16]$ performed plenty of correlative investigations through a turbocharged GDI engine fueled with high n-butanol content of gasoline blends. The tests showed that adding n-butanol increased cylinder pressure and its rise rate, promoted ignition and combustion stability, and shortened burning duration under wide-open throttle condition. Furthermore, these trends turned to be more significant when the n-butanol content increased from $30 \mathrm{vol} \%$ to $50 \mathrm{vol} \%$. He et al. [17] conducted experimental studies on an SI engine equipped with n-butanol/gasoline port injection and gasoline/n-butanol direct injection, and detected that their indicated mean effective pressures were almost the same when the total energy released per cycle was kept constant, but their combustion processes were dependent on fuel injection methods. Feng et al. [18] evaluated the burning behavior of a dual-injection engine utilizing gasoline port injection and n-butanol direct injection at stoichiometric ratio. The tests showed that the dual-injection strategy with n-butanol addition was an effective way to improve the fuel efficiency and engine output in comparison with PFI and GDI. But the anti-knock 
ability degraded at small n-butanol DI ratios. Venugopal et al. [19] found that pure n-butanol at higher throttle position while pure gasoline or B50S (50\% by mass) at lower throttle position could improve the combustibility and exhausts on a SI engine with two independent injectors in the intake port. Furthermore, injecting n-butanol just before the beginning of gasoline injection could reduce $\mathrm{HC}$ and $\mathrm{CO}$ emission even more than simultaneous injection at $60 \%$ throttle. From the studies described above, it was noticed that the independent injection could change the ratio and formation mode of n-butanol and gasoline flexibly in a working cycle while allowing full play to the advantages of different fuel properties in combustion process.

Although n-butanol as a substitute fuel can bring more benefits than short-chain alcohols, some potential issues still exist in n-butanol fueled engines. N-butanol has lower saturation pressure, higher latent heat of vaporization and longer ignition delay than that of gasoline [8]. So the problems of n-butanol fueled engines are mainly focused on slow evaporation rate, dissatisfactory atomization capability and ignition problems, which can offset the n-butanol positive properties and cause negative influence on combustion performance [20,21]. Hence, the application of $n$ butanol hybrid SI engines needs to be further improved for overcoming these drawbacks.

In comparison with conventional hydrocarbon fuels, hydrogen is another promising clean and potentially renewable energy source for engines, which has numerous advantages of fast propagation speed, wide flammability limits, short quenching distance and low ignition energy [22,23]. However, hydrogen fueled engines would inevitably suffer the effects of uncontrolled $\mathrm{NO}_{\mathrm{X}}$ emissions and weak power output due to its high flame temperature and low energy density [24,25]. Besides, the absence of infrastructures for hydrogen refueling and the difficulties facing implementation of hydrogen storage systems on vehicles limit the widespread use of pure hydrogen engines in the immediate future $[26,27]$. Therefore, adding a small proportion of hydrogen as auxiliary fuel is a favorable approach to improve the combustion properties of main fuel and then the engine performance, especially under small and medium load condition $[28,29,30,31]$.

Most previous investigations of hybrid hydrogen SI engines have been concentrated on improving the properties 
of common fossil fuels, such as gasoline, diesel and LNG for main working fuels [32-34]. Therefore, the potential of hydrogen improving the n-butanol combustion performance and enhancing its adaptability to combustion environments can be seen from the evidence presented by previous studies. However, due to the inability of n-butanol to be premixed with hydrogen like gasoline, combined injection technique is applied as injecting two types of fuel respectively through two independent injectors per working cycle. Studies have shown that engines demonstrated different advantages with different hydrogen injection locations [35]. The hydrogen direct injection (HDI) brings unique superiorities for avoiding low volume efficiency and two major abnormal combustion phenomena, backfiring and pre-ignition, which are caused by hydrogen port injection [36,37]. At the same time, n-butanol port injection can eliminate the undesirable cooling effect caused by injecting directly into cylinder. So an n-butanol/gasoline port injection combined with HDI method is put forward, which expects to utilize the hydrogen's favorable combustion properties to offset the shortcomings of n-butanol blending engines.

However, there are few previous studies have been investigated on the impact of hydrogen supplement on nbutanol fueled engines. Su et al. [38] found that a more stable combustion with shortened ignition delay and rapid combustion duration could be gained by $3 \mathrm{vol} \%$ hydrogen supplement on an n-butanol rotary engine under lean burn condition. Also an additional benefit of reducing $\mathrm{NO}_{\mathrm{X}}$ emission was achieved through lean combustion strategies on both n-butanol and hydrogen/n-butanol rotary engines. Yang et al. [39] compared the performance of a hydrogen/gasoline and hydrogen/n-butanol fueled rotary engine with dual-fuel port injection. They found that the hydrogen/n-butanol shared highly similar performance with hydrogen/gasoline and their performance could be improved by hydrogen enrichment. Sukjit et al. [40] investigated the impact of butanol and hydrogen supplement on combustion performance of a biodiesel compression ignition engine. The test indicated that the hydrogen supplement could counteract the increased $\mathrm{HC}$ emission caused by butanol blends and further reduce the $\mathrm{CO}$ and PM emissions. Raviteja et al. [41] conducted experimental studies on a gasoline/n-butanol blends fueled SI engine with hydrogen supplement at stoichiometric ratio. They concluded that 30vol\% n-butanol blend was a better alternative to pure 
gasoline and both enriched hydrogen and oxygen content could realize more complete combustion, higher thermal efficiency and lower $\mathrm{CO}$ and $\mathrm{HC}$ emissions, but increased the $\mathrm{NO}_{\mathrm{x}}$ emissions. However, it is noticed that all the studies mentioned above were performed using hydrogen intake port injection.

From our previous work, the combustion characteristic and emission performance showed great improvement by hydrogen direct injection on a pure gasoline or pure n-butanol SI engine $[28,35,42,43,44]$. Some aspects such as hybrid approaches, gaseous and particle emissions on an n-butanol blending gasoline engine have also been conducted $[45,46]$. However, the combustion performance of n-butanol/gasoline blended fuel combined with hydrogen supplementary fuel has not been studied yet. Therefore, in this study, to compare and analyze the relationship between hydrogen and n-butanol addition and other variables, three injection modes with five n-butanol volume ratios were considered on the basis of combined injection technique, including n-butanol/gasoline port injection $\left(\mathrm{NG}_{\mathrm{P}}\right)$ mode, $\mathrm{n}$-butanol/gasoline combined injection $\left(\mathrm{NG}_{\mathrm{PD}}\right)$ mode and $\mathrm{n}$-butanol/gasoline with hydrogen combined injection $\left(\mathrm{NG}_{\mathrm{PH}}\right)$ mode. Comparing the $\mathrm{NG}_{\mathrm{P}}$ mode and $\mathrm{NG}_{\mathrm{PD}}$ mode means contrasting the difference between single injection and combined injection, and further comparing the $\mathrm{NG}_{\mathrm{PD}}$ mode and $\mathrm{NG}_{\mathrm{PH}}$ mode can obtain the effect of hydrogen direct injection.

\section{Table 1}

Specifications of alcohols [8], gasoline [8] and hydrogen [23].

\begin{tabular}{|c|c|c|c|c|c|}
\hline & Methanol & Ethanol & n-Butanol & Gasoline & Hydrogen \\
\hline Molecular formula & $\mathrm{CH}_{3} \mathrm{OH}$ & $\mathrm{C}_{2} \mathrm{H}_{5} \mathrm{OH}$ & $\mathrm{C}_{4} \mathrm{H}_{9} \mathrm{OH}$ & $\mathrm{C}_{5}-\mathrm{C}_{12}$ & $\mathrm{H}_{2}$ \\
\hline Density $(\mathrm{kg} / \mathrm{L})$ at $20^{\circ} \mathrm{C}$ & 0.792 & 0.789 & 0.808 & $0.72-0.78$ & 0.09 (at 1 bar) \\
\hline Viscosity (Pa-s) at $20^{\circ} \mathrm{C}$ & 0.61 & 1.20 & 3.64 & $0.28-0.59$ & - \\
\hline Research octane number & $109-136$ & $108-129$ & $96-98$ & $80-98$ & - \\
\hline Cetane number & $3-5$ & $5-8$ & $17-25$ & $5-25$ & - \\
\hline Lower heating value (MJ/kg) & 19.9 & 26.8 & 33.1 & 42.7 & 119.7 \\
\hline Heat of vaporization $(\mathrm{MJ} / \mathrm{kg})$ & 1.2 & 0.90 & 0.43 & $0.31-0.34$ & - \\
\hline Saturation pressure $(\mathrm{kPa})$ at $38^{\circ} \mathrm{C}$ & 31.69 & 13.8 & 2.27 & 31.01 & - \\
\hline Stoichiometric ratio & 6.49 & 9.02 & 11.21 & 14.7 & 34.5 \\
\hline Laminar flame speed $(\mathrm{cm} / \mathrm{s})$ at $25^{\circ} \mathrm{C}$ & - & - & $48-53$ & $37-43$ & 185 (at 1 bar) \\
\hline Flammability limits (\%vol.) & $6.0-36.5$ & 4.3-19 & $1.4-11.2$ & $0.6-8$ & $4-76$ \\
\hline
\end{tabular}




\begin{tabular}{llllll}
\hline Oxygen content $(\%$ weight $)$ & 50 & 34.8 & 21.6 & 0 & 0 \\
Auto-ignition temperature $\left({ }^{\circ} \mathrm{C}\right)$ & 470 & 434 & 385 & $\sim 300$ & 585 \\
Minimum ignition energy $(\mathrm{mJ})$ & 0.215 & - & - & 0.24 & 0.02 \\
\hline
\end{tabular}

\section{Experimental setup and procedure}

\subsection{Experimental setup}

The experiment was conducted on a combined injection SI engine with primary technical specifications as listed in Table 2 and its experimental setup as shown by the scheme in Fig. 1. The n-butanol/gasoline mixed fuel port supply system and direct supply system were used for pre-mixing and directly injecting the mixed fuel, respectively. Meanwhile an extra gas transportation line was added to the direct supply system for hydrogen direct injection. For separately controlling the engine ignition timing, n-butanol/gasoline and hydrogen injection pulse width and timing, a self-developed ECU was adopted. Fig. 2 illustrates the methods of combined injection.

In terms of the experimental equipment, a CW160 eddy current dynamometer was coupled with the engine to control and measure the torque and engine speed. The in-cylinder pressure was obtained from a GU13Z-24 pressure transducer while the crank angle signals were collected through a Kistler-2614B4 crank angle encoder. A Lambda meter LA4 was installed to monitor the excess air ratio. The mass flow rate of $n$-butanol/gasoline was acquired by DF-2420. A SIRIUS combustion analyzer was adopted to analyze the combustion properties. The $\mathrm{HC}, \mathrm{CO}$ and $\mathrm{NO}_{\mathrm{X}}$ emissions were measured via a DIGas 4000 light five-component exhaust gas analyzer. Detailed information about the experimental facilities is provided in Table 3. Additionally, the experiment used $99.7 \%$ purity n-butanol blending RON 97 standard gasoline with $99.99 \%$ volume fraction hydrogen. 


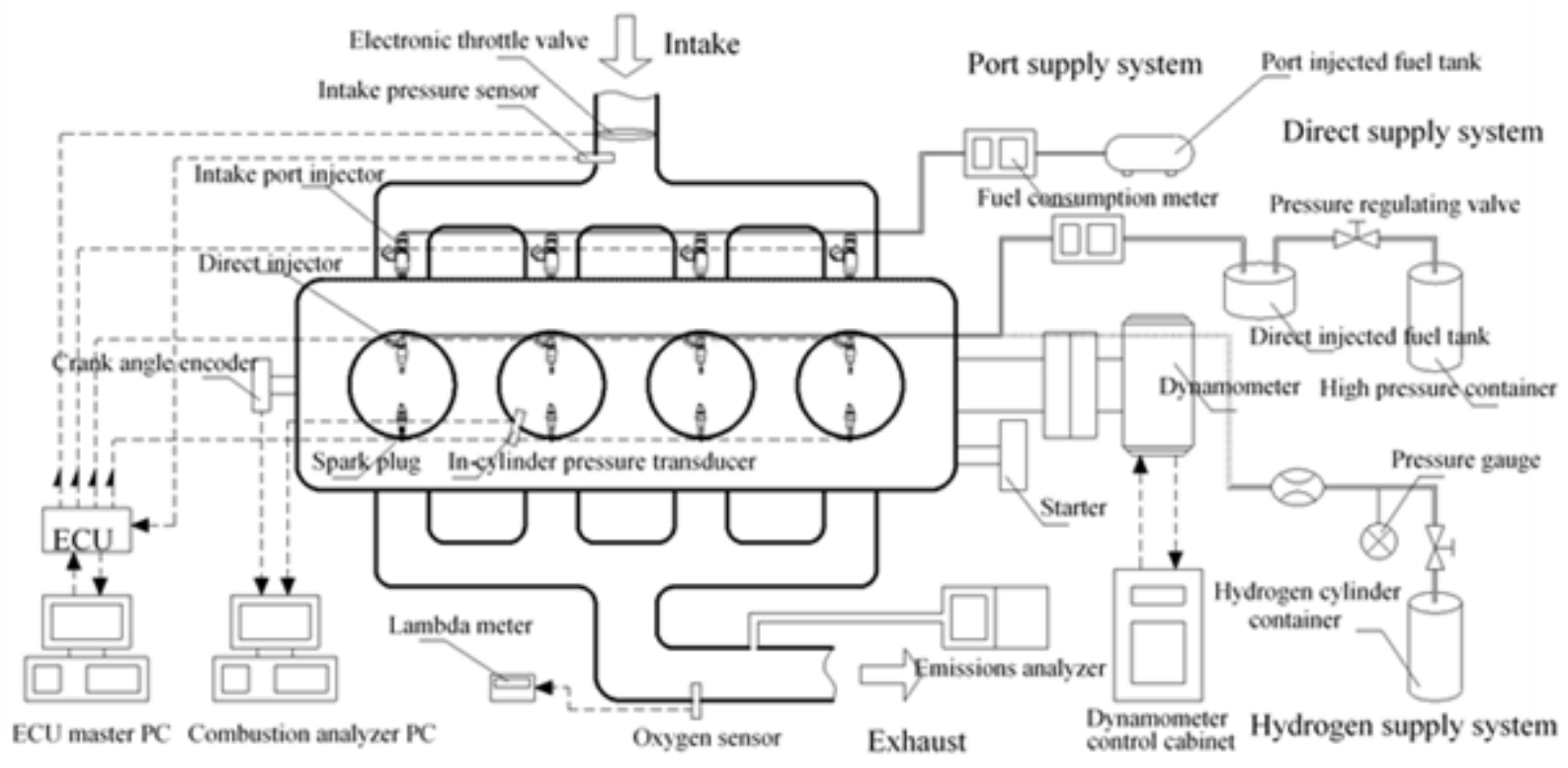

Fig. 1. Schematic diagram of the experimental setup

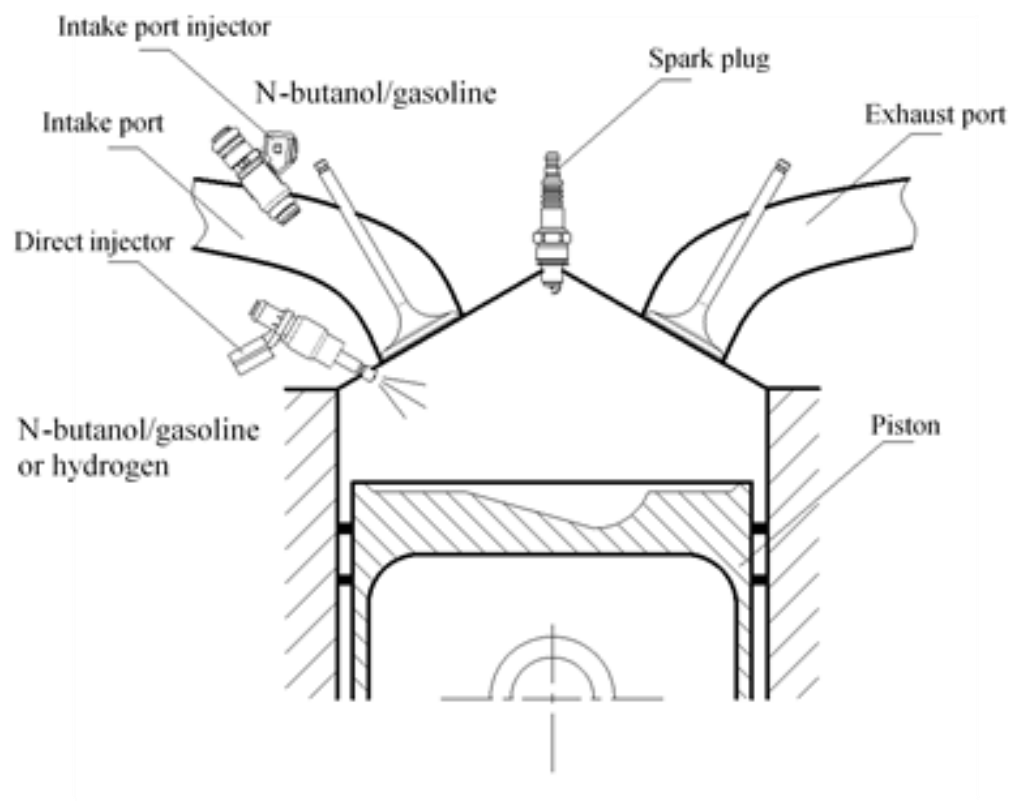

Fig. 2. Schematic diagram of the combined injection modes

Table 2

Specifications of the experimental engine.

\begin{tabular}{ll}
\hline Engine type & Inline four cylinder, spark-ignited, combined injection \\
\hline Displacement & $1.984 \mathrm{~L}$ \\
Bore $\times$ stroke & $82.5 \mathrm{~mm} \times 92.8 \mathrm{~mm}$ \\
Compression ratio & $9.6: 1$ \\
Rated power/ speed & $132 \mathrm{~kW} /(4000 \mathrm{r} / \mathrm{min}-6200 \mathrm{r} / \mathrm{min})$ \\
Rated torque/ speed & $320 \mathrm{Nm} /(1500 \mathrm{r} / \mathrm{min}-4500 \mathrm{r} / \mathrm{min})$ \\
\hline
\end{tabular}


Table 3

Experimental apparatus specifications.

\begin{tabular}{lllll}
\hline Apparatus & Parameter & Manufacturer & Type & Resolution \\
\hline Dynamometer & Torque & Luoyang Nanfeng & CW 160 & $\leq \pm 0.4 \%$ \\
& Engine speed & & & $\leq \pm 1 \mathrm{r} / \mathrm{min}$ \\
Lambda meter & Excess air ratio & ETAS Engineering TOOLS & LAMBDA LA4 & $\leq \pm 1.5 \%$ \\
Fuel consumption meter & Gasoline mass flow rate & ONO SOKKI & DF-2420 & $\leq \pm 0.01 \mathrm{~g} / \mathrm{s}$ \\
In-cylinder pressure transducer & In-cylinder pressure & AVL Company & GU 13Z-24 & $\leq \pm 0.3 \%$ \\
Crank angle encoder & Crank angle & Kistler Instrument Company & Kistler-2614B4 & $\leq \pm 0.5^{\circ}$ \\
Combustion analyzer & Heat release rate & DEWESoft Company & SIRIUS & $\leq \pm 0.1 \%$ \\
& Cycle-to-cycle variation & & & $\leq \pm 0.1 \%$ \\
Emission analyzer & CO emission & AVL Company & DIGas 4000 light & $\leq \pm 0.01 \%$ \\
& HC emission & & & $\leq \pm 1 \mathrm{ppm}$ \\
& NOx emission & & & $\leq \pm 1 \mathrm{ppm}$ \\
\hline
\end{tabular}

\subsection{Experimental procedure}

In the experiments, three injection modes with five n-butanol volume ratios were selected for studying the impact of injection mode on combustion and emission performance of an n-butanol/gasoline SI engine. The ratio of $n$ butanol blending volume was adjusted from 0 to $100 \%$ with an interval of $25 \%$ and it was defined as follow:

$$
v_{N}=\frac{V_{n-\text { butanol }}}{V_{n-\text { butanol }}+V_{\text {gasoline }}}
$$

In Eq. (1), $v_{N}$ denoted the n-butanol volume ratio, $V_{n \text {-butanol }}$ and $V_{\text {gasoline }}$ represented the blending volume of n-butanol and gasoline, respectively. And for verifying the difference of input heat between test conditions caused by different blending volume of n-butanol and gasoline, the total mixed fuel input heat values at five $v_{N}$ values under stoichiometric ratio condition were calculated as listed in Table 4 . The total heat value only decreased by $0.838 \%$ when the $v_{N}$ was from 0 to $100 \%$, which means the effect of total mixed fuel input heat can be negligible.

Hence, to keep the total heat value constant, the fuel direct injection fraction was defined as follows:

$$
\varphi_{\text {direct }}=\frac{Q_{\text {direct }}}{Q_{\text {direct }}+Q_{\text {port }}}
$$


In Eq. (2), $\varphi_{\text {direct }}$ denoted the fraction of fuel direct injection, $Q_{\text {direct }}$ and $Q_{\text {port }}$ denoted the heat generated by fuel direct injection and port injection respectively. The sum of $Q_{\text {direct }}$ and $Q_{\text {port }}$ represented the total input heat. Based on our previous work, the $\varphi_{\text {direct }}$ was set as a $10 \%$ fixed value in this experiment [47]. For NGPD mode, the $\varphi_{\text {direct }}$ is equal to the mass ratio of direct injection mixed fuel to total mixed fuel. And for $\mathrm{NG}_{\mathrm{PH}}$ mode, the total heat value would theoretically exceed by $1.84 \%$ when the hydrogen completely replaced the direct injection mixed fuel since their different lower heating value and oxygen consumption under stoichiometric ratio condition [47]. This difference was within the allowable range of the experiment, so the total heat by three injection modes was considered to be the same. The port injection timing and direct injection timing was fixed at $300^{\circ} \mathrm{CA} \mathrm{BTDC}$ and $100^{\circ} \mathrm{CA}$ BTDC, respectively $[46,48]$. The pressure of port injection and direct injection was 300 and 5,000 kPa, respectively $[46,48]$. The ignition timing was set at the minimum advance for best torque (MBT). The engine was operated under the speed of $1200 \mathrm{r} / \mathrm{min}$ and $30 \mathrm{kPa}$ intake manifold absolute pressure at stoichiometric ratio as a typical small and medium load urban condition. Each operation point was recorded for 200 cycles.

\section{Table 4}

Total heat value at different n-butanol volume ratios under stoichiometric ratio.

\begin{tabular}{l|c|c|c|c|c}
\hline N-butanol volume ratio (\%) & 0 & 25 & 50 & 75 & 100 \\
\hline Volumetric heating value (kJ/L) & 31.538 & 31.478 & 31.408 & 31.346 & 31.273 \\
Heating value reduction in comparison & 0 & -0.190 & -0.412 & -0.609 & -0.838 \\
with pure gasoline (\%) & & & & & \\
\hline
\end{tabular}

\section{Results and discussion}

\subsection{Effect of injection mode on combustion characteristics}

\subsubsection{Cylinder pressure}

Fig. 3 shows the variation of cylinder pressure with crank angle for three modes at various n-butanol volume ratios. 
When the $v_{N}=0$, the $\mathrm{NG}_{\mathrm{P}}$ mode can be deemed as pure gasoline port injection (GPI) mode. So its cylinder pressure curve can regard as the reference line to compare the pressure curves of other $v_{N}$ under different modes. Under each $v_{N}$, Fig. 3 shows that the peak cylinder pressure of $\mathrm{NG}_{\mathrm{PD}}$ and $\mathrm{NG}_{\mathrm{PH}}$ combined modes is all higher than that of $\mathrm{NG}_{\mathrm{P}}$ single mode and the corresponding crank angle is slightly advanced even at the MBT ignition timing. The reason may lie in the concentration distribution of mixture inside cylinder [49]. Through combined injection, a stable homogeneous lean mixture can fill the cylinder during the intake stroke and subsequently a local rich concentration area around the spark plug can be concentrated during the compression stroke, forming a stratified mixture that realizes the reliable ignition and complete fuel combustion. So the cylinder pressure increases and even the pure nbutanol can maintain better combustion performance than GPI through combined injection modes. In further comparison of the two combined injection modes, the peak cylinder pressure continuously increases with the addition of hydrogen under each $v_{N}$. This is mainly because the favorable combustion characteristics of hydrogen [23]. Its wide flammability limits, fast diffusion rate and low minimum ignition energy can make up for the innate problems of poor evaporation and atomization and ignition delay caused by n-butanol, allowing the cylinder pressure to reach a higher peak more rapidly.

In addition, the values of the peak cylinder pressure and its corresponding phase at different $v_{N}$ under three injection modes are shown in Fig. 4. It can be seen form Fig. 4, under each injection mode, the peak cylinder pressure initially rises and subsequently decreases with the increasing $v_{N}$. This result may be explained by the physicochemical properties of n-butanol [50]. Firstly, the oxygen atom contained in n-butanol can lead to a more complete combustion. Secondly, the high laminar flame speed of n-butanol can increase the degree of constant-volume combustion. These advantageous factors bring the cylinder pressure to the maximum at $v_{N}=25 \%$ and still promote a slight beneficial effect when the $v_{N}=50 \%$. However, as the $v_{N}$ continues to increase, the drawbacks of slow evaporation rate and dissatisfactory atomization capability of n-butanol gradually reveal out, leading to a drop in cylinder pressure. Fig. 4 also shows that the corresponding phases of peak cylinder pressure are all concentrated 
within the scope of 11 to $14^{\circ} \mathrm{CA}$ ATDC since the ignition timing is set to MBT to obtain the optimal combustion phase.

When the $v_{N}$ is constant, the main difference in three modes is the concrete values of the peak cylinder pressure. Compared to $\mathrm{NG}_{\mathrm{P}}$ mode, the peak cylinder pressure increases $6.80 \%, 6.43 \%, 5.98 \%, 4.55 \%$ and $4.13 \%$ at $v_{N}=0$, $v_{N}=25 \%, v_{N}=50 \%, v_{N}=75 \%$ and $v_{N}=100 \%$ respectively under $\mathrm{NG}_{\mathrm{PD}}$ mode, which represents a sustained downward trend with the increasing $v_{N}$. This tendency occurs because the fuel injected directly into the cylinder becomes harder to vaporize around the spark plug with the increase of $v_{N}$, leading to the less significant effect of $\mathrm{NG}_{\mathrm{D}}$. Meanwhile the peak cylinder pressure of $\mathrm{NG}_{\mathrm{PH}}$ mode is $11.63 \%$ higher on average than that of $\mathrm{NG}_{\mathrm{P}}$ mode.

Hence, the peak cylinder pressure is increased by combined injection and further adding hydrogen can make a greater improvement under each $v_{N}$.

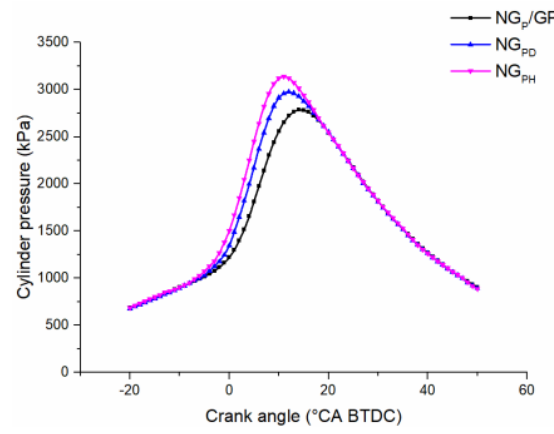

a. $v_{N}=0$

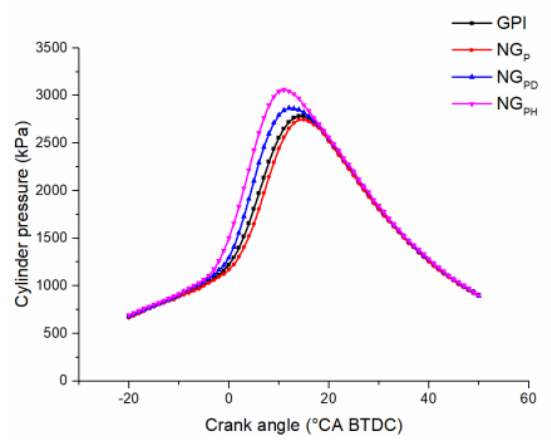

d. $v_{N}=75 \%$

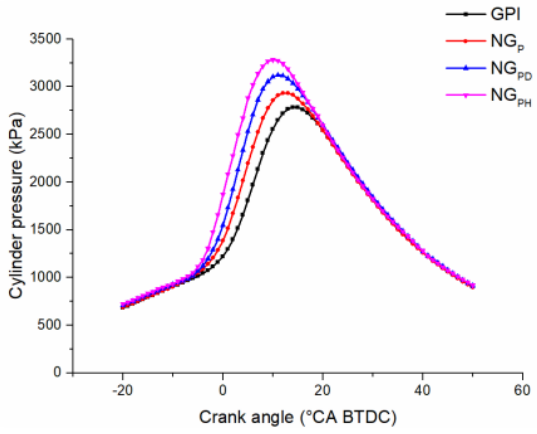

b. $v_{N}=25 \%$

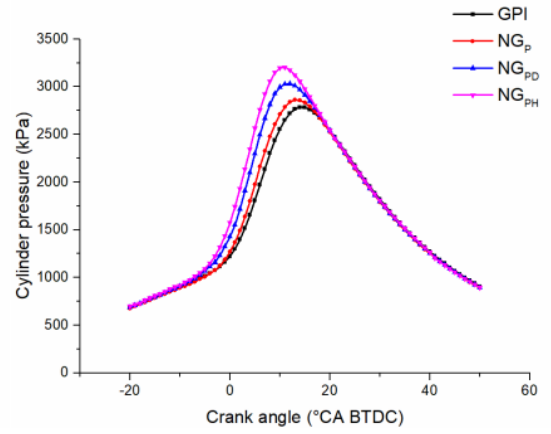

c. $v_{N}=50 \%$

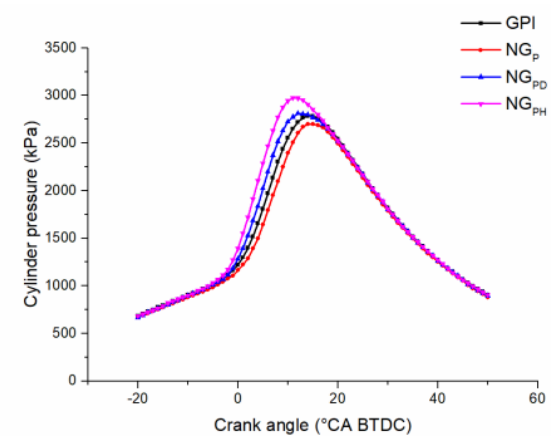

e. $v_{N}=100 \%$

Fig. 3. Cylinder pressure versus crank angle at different n-butanol volume ratios under different modes 


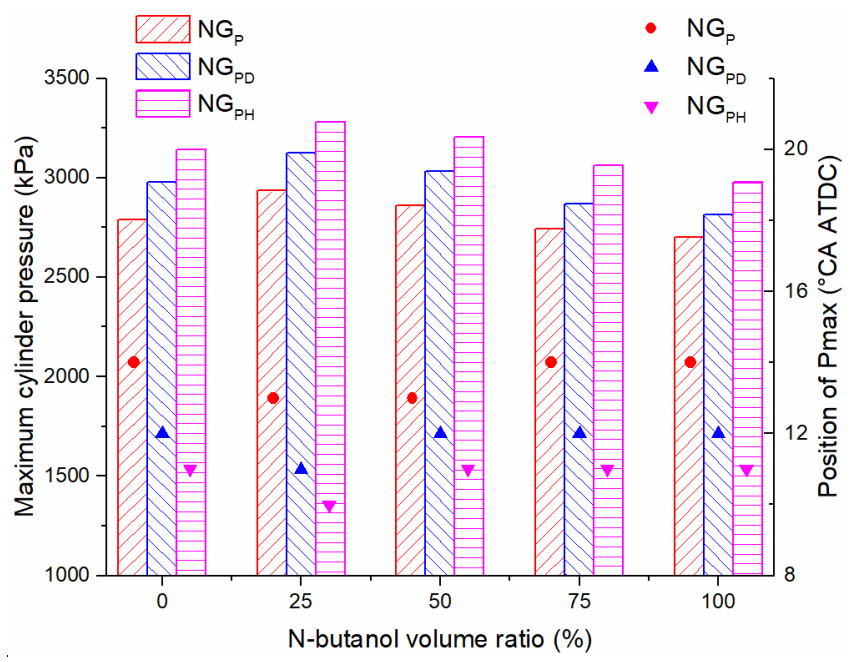

Fig. 4. Peak cylinder pressure and its phase at different n-butanol volume ratios under different modes

\subsubsection{Heat release rate}

Fig.5 illustrates that the regularity of peak heat release rate versus $v_{N}$ under each injection mode, which reveals a similar tendency to the peak cylinder pressure. And when $v_{N}$ is constant, for example, at $v_{N}=50 \%$, the peak heat release rate increases and its phase moves forward to the TDC simultaneously in a sequence of $\mathrm{NG}_{\mathrm{P}}, \mathrm{NG}_{\mathrm{PD}}$ and $\mathrm{NG}_{\mathrm{PH}}$ injection mode as shown in Fig. 6. Through combined injection, a local mixture-enriched area near the spark plug can be formed because of the geometric structure of piston top and moderate tumble motions, which contributes to obtaining a steady flame kernel. Through the reliable ignition and rapid outward propagation of the flame front benefitted from the steady flame kernel, the surrounding mixture can be quickly ignited, thereby increasing the heat release rate and facilitating the concentration of heat release process. Furthermore, hydrogen supplement can increase the mixture combustion rate, especially in the flame propagation inception phase [51], which indicates the slope of heat release rate curve can become steeper as more mixture heat releases in a shorter period. Therefore, an accelerated and concentrated heat release process can be achieved by $\mathrm{NG}_{\mathrm{PD}}$ and $\mathrm{NG}_{\mathrm{PH}}$ injection mode. 


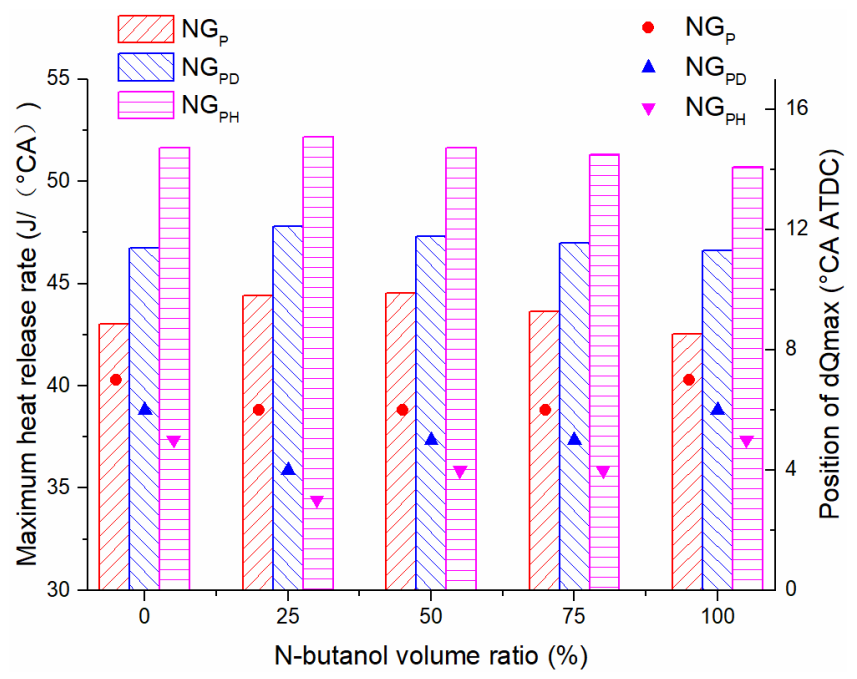

Fig. 5. Peak heat release rate and its phase at different n-butanol volume ratios under different modes

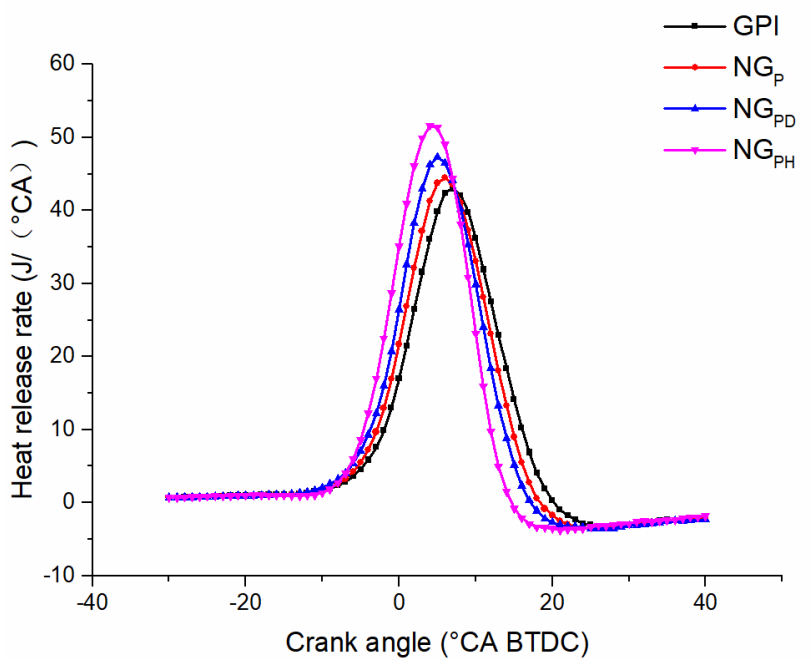

Fig. 6. Heat release rate versus crank angle at $50 \%$ n-butanol volume ratio under different modes

\subsubsection{Flame development duration}

The flame development duration (CA0-10) is defined as the crank angles from the beginning of spark ignition to the mass of burned fuel reaching 10\%, and the rapid combustion duration (CA10-90) is defined as the crank angles from $10 \%$ to $90 \%$ of the mass of burned fuel in this paper. The variation of flame development duration and rapid combustion duration with $v_{N}$ under three modes are shown in Fig. 7 and 8, respectively.

Fig. 7 shows that with the increasing $v_{N}$, the flame development duration first shortens then gradually lengthens under $\mathrm{NG}_{\mathrm{P}}$ mode, whereas the effect of $v_{N}$ on flame development duration is subdued under $\mathrm{NG}_{\mathrm{PD}}$ and $\mathrm{NG}_{\mathrm{PH}}$ mode. 
The flame development duration obtains the minimum at $v_{N}=25 \%$ can be explained by the dehydrogenation reaction of n-butanol during the early combustion phase, which provides large amounts of $\mathrm{OH}$ free radicals to facilitate the chemical reaction rate of gasoline in the initial combustion stage [52]. Meanwhile, the gasoline with small $v_{N}$ has shorter flame development duration also because the n-butanol has a faster laminar flame speed [53]. However, the high latent heat of vaporization and low saturated vapor pressure are two other important thermodynamic properties of n-butanol that affect early combustion [54]. The strong cooling effect of in-cylinder charge and the long time of complete evaporation can offset the positive properties of $n$-butanol and cause negative influence on shortening flame development duration when the $v_{N}$ continues to increase.

For $\mathrm{NG}_{\mathrm{PD}}$ and $\mathrm{NG}_{\mathrm{PH}}$ mode, the same as analyzing the heat release process, the steady flame kernel formed by combined injection and the favorable combustion characteristics of hydrogen can contribute to the reliable ignition and early flame propagation, weakening the effect of $v_{N}$ on flame development duration and shortening the initial combustion phase. The flame development duration of $\mathrm{NG}_{\mathrm{PD}}$ and $\mathrm{NG}_{\mathrm{PH}}$ mode is shortened by $3.28{ }^{\circ} \mathrm{CA}$ and $6.61^{\circ} \mathrm{CA}$ on average respectively as compared to $\mathrm{NG}_{\mathrm{P}}$ mode.

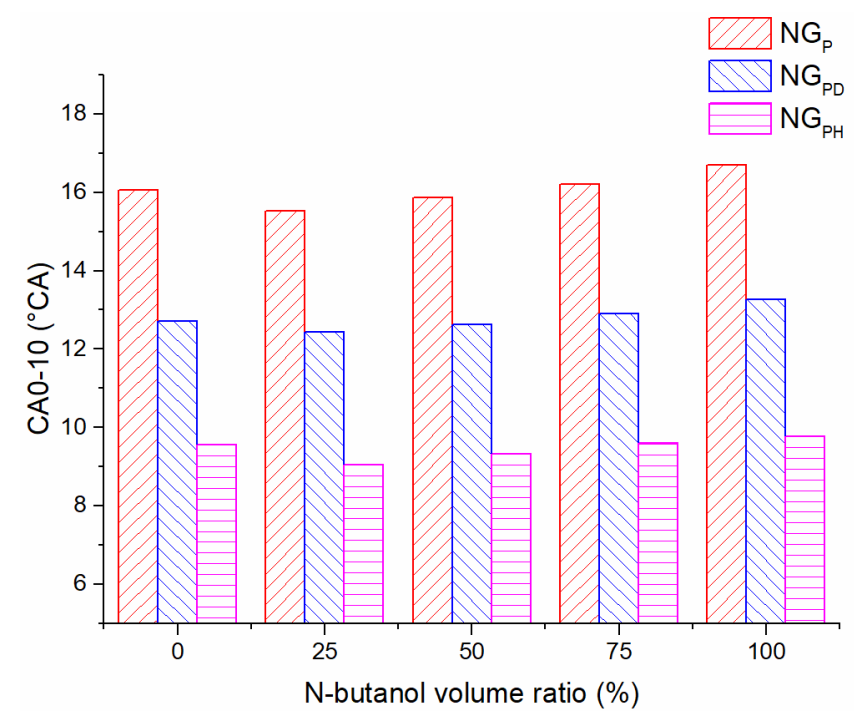

Fig. 7. Flame development duration versus n-butanol volume ratios under different modes

\subsubsection{Rapid combustion duration}


Fig. 8 shows that the rapid combustion duration continuously shortens with the increasing $v_{N}$ under each injection mode. Due to the molecular chain of n-butanol is shorter than the average molecular chain of gasoline, once the n-butanol is ignited, coupled with its faster laminar flame speed, the rapid combustion duration will be shortened [55]. Also the rapid combustion duration of $\mathrm{NG}_{\mathrm{PD}}$ and $\mathrm{NG}_{\mathrm{PH}}$ mode is shortened by $0.64{ }^{\circ} \mathrm{CA}$ and $1.74^{\circ} \mathrm{CA}$ on average respectively than that of NGp mode. Thus, it can be concluded that the combined injection and hydrogen addition have a definite effect on total combustion duration (CA0-90).

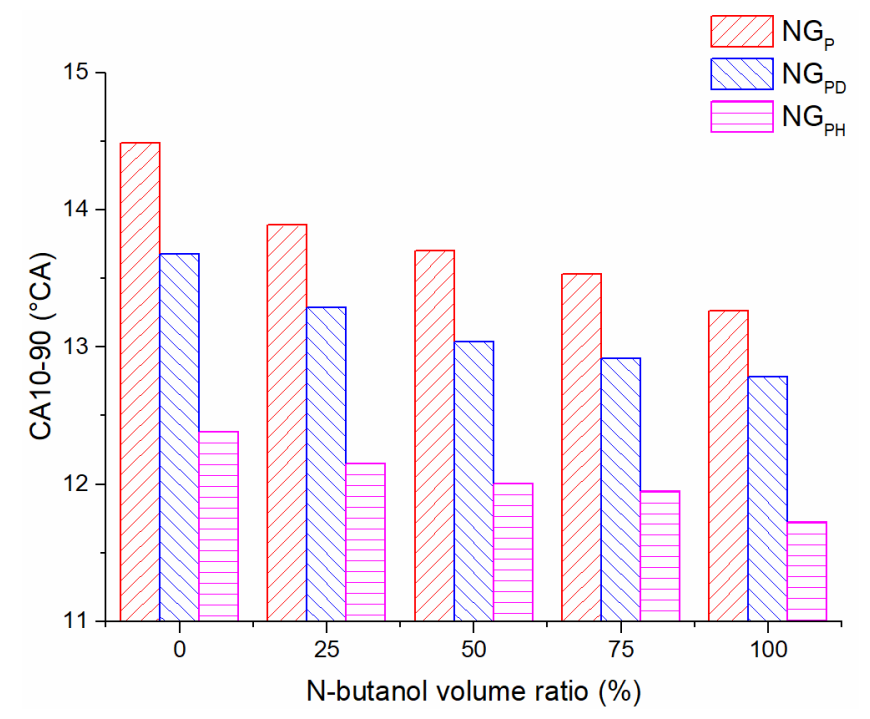

Fig. 8. Rapid combustion duration versus n-butanol volume ratios under different modes

\subsubsection{Peak cylinder temperature}

As shown in Fig. 9, the peak cylinder temperature initially rises a little before continuously declining with the increase of $v_{N}$ under all injection modes. Since n-butanol has a lower stoichiometric air-fuel ratio and lower heating value then gasoline, the mass of mixed fuel injected per cycle needs to be increased as the $v_{N}$ is incremental under the same excess air coefficient condition. Plus the n-butanol's high latent heat of vaporization makes a more prominent heat absorption of the blends with large $v_{N}$ in comparison with pure gasoline [56]. Thus the in-cylinder temperature decreases under large $v_{N}$ condition, while the mixture formation quality turns worse and the incomplete combustion becomes obvious, also reflecting in the lower heat release and lower cylinder pressure. The 
peak cylinder temperature at $v_{N}=25 \%$ is a little higher than that at $v_{N}=0 \%$ can be explained by the positive properties of $\mathrm{n}$-butanol, which is the same as the process of analyzing the combustion performance. In addition, the in-cylinder temperature is accumulated by the heat generated from combustion, implying that the concentrated heat release process and less heat transfer loss will result in a higher peak cylinder temperature. Therefore, the peak cylinder temperature of $\mathrm{NG}_{\mathrm{PD}}$ and $\mathrm{NG}_{\mathrm{PH}}$ modes is higher than that of $\mathrm{NG}_{\mathrm{P}}$ mode due to the combination of high peak release rate and short combustion duration, which can also be demonstrated by Fig. 5 and Fig. 8 .

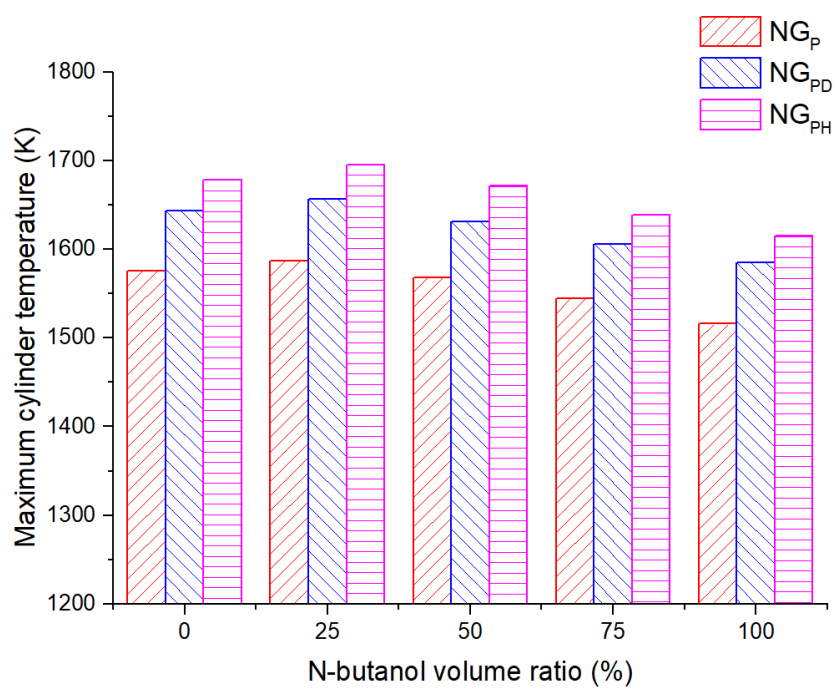

Fig. 9. Peak cylinder temperature versus n-butanol volume ratios under different modes

\subsubsection{Brake mean effective pressure}

The brake mean effective pressure (BMEP) represents the effective work output of the engine under per piston swept volume, which is a key parameter for measuring the engine power performance [25]. In addition, as the total heat generated remains the same for n-butanol/gasoline mixed fuel or with hydrogen, the brake thermal efficiency is directly proportional to the BMEP under three modes. Fig. 10 shows that the trend in which the BMEP first rises and then falls with the increasing $v_{N}$ is the same for all of the modes. The physico-chemical properties of n-butanol can explain this result. Firstly, the n-butanol can make the combustion more complete as an oxygenated fuel. Secondly, the high latent heat of vaporization of n-butanol can reduce the mixture temperature inside cylinder, thus reducing 
the heat transfer loss through the cylinder wall as well. Thirdly, the n-butanol has a faster laminar flame speed than gasoline, which can increase the degree of constant-volume combustion. These beneficial characteristics of n-butanol can still lead to a higher BMEP compared to pure gasoline when the $v_{N}$ is 50\%. As the $v_{N}$ continues to increase, the disadvantages of poor evaporation and atomization performance of n-butanol gradually emerge, causing a decline in the BMEP.

Fig. 10 also shows that the BMEP of $\mathrm{NG}_{\mathrm{PD}}$ mode is all higher than that of $\mathrm{NG}_{\mathrm{P}}$ mode under each $v_{N}$ and the BMEP can continue to increase with adding hydrogen. The reason is that the mixture concentration distribution inside cylinder formed by combined injection and the favorable combustion characteristics of hydrogen can shorten the total combustion duration and lessen the incomplete combustion, allowing the combustion much closer to ideal constant-volume combustion and more fuel energy can be used for engine working [43]. On the other hand, as shown in fig.11, the lower exhaust temperature of combined injection modes can also reflect that more heat is used to produce work as the same energy input [47]. Besides, the direct injection does not occupy the intake charge and can increase the volumetric efficiency. It is also noted that the BMEP values of $\mathrm{NG}_{\mathrm{PD}}$ and $\mathrm{NG}_{\mathrm{PH}}$ mode at $v_{N}=100 \%$ are both higher than that of $\mathrm{NGP}_{\mathrm{P}}$ mode at $v_{N}=0 \%$, so using combined injection and hydrogen supplement can evidently improve the engine power performance.

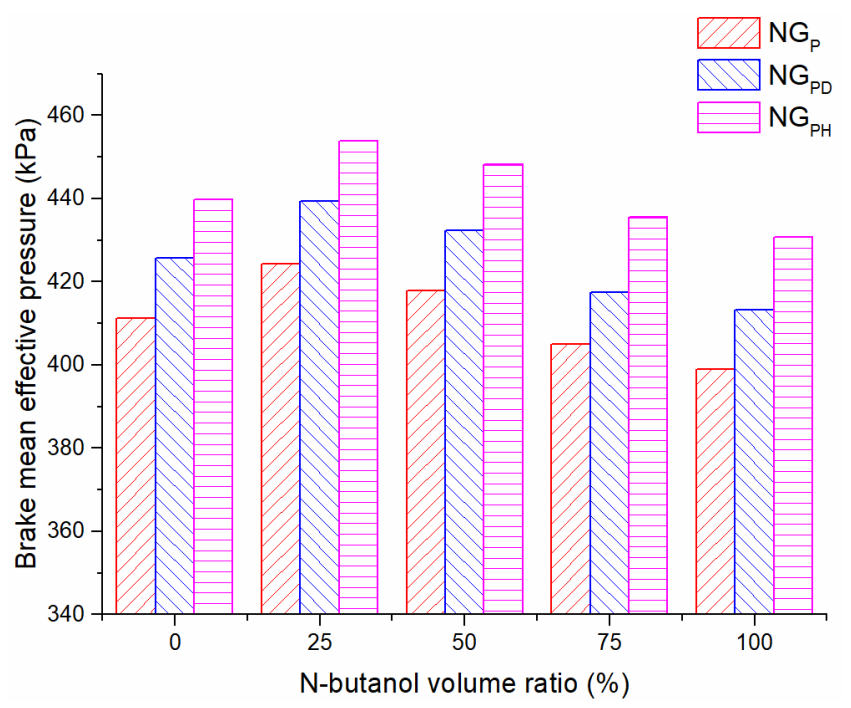

Fig. 10. Brake mean effective pressure versus n-butanol volume ratios under different modes 


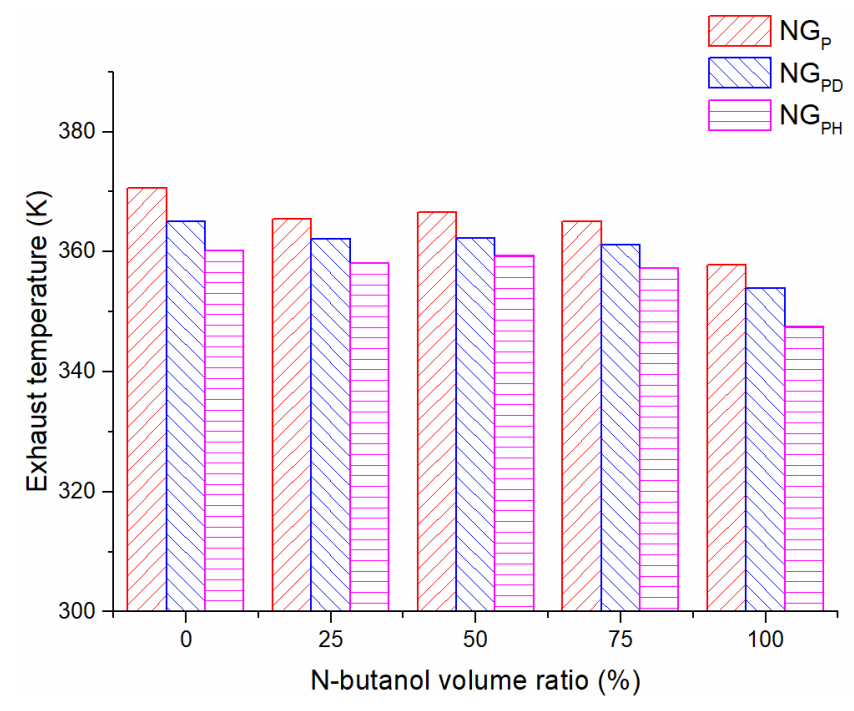

Fig. 11. Exhaust temperature versus n-butanol volume ratios under different modes

\subsubsection{Coefficient of variation}

To compare the combustion stability of three modes, Fig. 12 shows that the effect of cyclic variation on coefficient of variation $(\mathrm{COV})$ versus $v_{N}$ at stoichiometric ratio. As shown, the COV initially falls and subsequently rises as the $v_{N}$ is incremental under each injection mode. When the $v_{N}=25 \%$, because of the small amount of n-butanol blending into gasoline, the increased oxygen content and laminar flame speed of mixed fuel can improve the combustion performance. Then, as $v_{N}$ keeps increasing, the increased latent heat of vaporization and the reduced saturated vapor pressure of the mixed fuel result in a worse atomization quality, which is not favorable to forming the mixture inside cylinder and makes the incomplete combustion more obvious. Thus, there is a minimum COV at $v_{N}=25 \%$ and a maximum COV at $v_{N}=100 \%$ under each injection mode.

Fig.12 also shows that the COV of two combined injection modes is all lower than that of port injection mode and the $\mathrm{COV}$ can be further controlled below $1.0 \%$ by hydrogen addition. The same as analyzing the heat release process, through combined injection, the local rich concentration area around the spark plug can heighten the reliability of ignition and accelerate the speed of flame propagation, which is shown to weaken the interference from combustion environment and reduce the COV. For $\mathrm{NG}_{\mathrm{PH}}$ injection mode, the hydrogen addition can reduce the ignition energy, 
increase the combustion rate and further make up for the issues of poor combustion performance of n-butanol. Hence, a stable flame developing process during the inception phase of ignition can be realized by means of hydrogen, which is effective in improving the combustion stability [51].

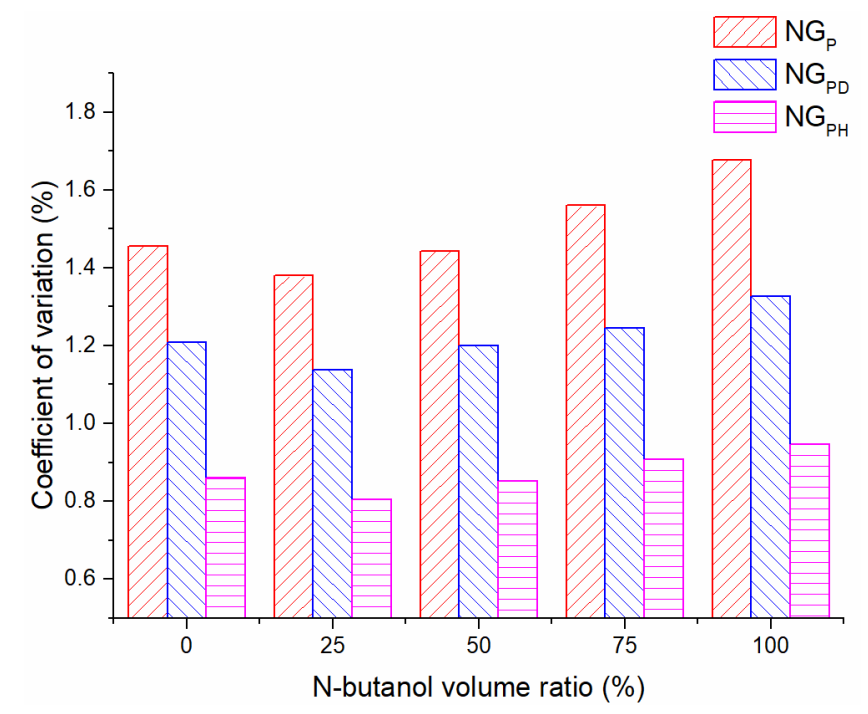

Fig. 12. Coefficient of variation versus n-butanol volume ratios under different modes

\subsection{Effect of injection mode on emission characteristics}

\subsubsection{HC emission}

Fig. 13 shows the HC emissions, which initially fall and then rise with the increasing $v_{N}$ for all injection modes.

This occurs because the increase of oxygen content introduced by n-butanol can produce large amounts of $\mathrm{OH}$ free radicals [52]. Its strong oxidizing property promotes the process of $\mathrm{C}-\mathrm{H}$ chain reaction and helps the mixed fuel burn more completely, and can even continuously oxidize the unburned hydrocarbons in the late combustion stage. As the $v_{N}$ continues to increase, the low combustion temperature inside cylinder, the local fuel concentrated area and the flame quenching at combustion chamber wall become the primary sources of $\mathrm{HC}$ emissions. Thus, under each injection mode, the $\mathrm{HC}$ emissions obtain the minimum at $v_{N}=25 \%$ and reach the maximum at $v_{N}=100 \%$. It can also be said that the $v_{N}$ lower than $50 \%$ will all contribute to reducing the $\mathrm{HC}$ emissions compared to pure gasoline. 
Under each $v_{N}$, Fig. 13 also shows that the $\mathrm{HC}$ emissions of $\mathrm{NG}_{\mathrm{PD}}$ and $\mathrm{NG}_{\mathrm{PH}}$ combined modes are both lower than that of $\mathrm{NG}_{\mathrm{P}}$ mode. The evident reduction of $\mathrm{HC}$ emissions through combined injection can be attributed to the steady flame kernel formed in initial stage, which is conducive to igniting reliably and setting fire to the ambient mixed fuel rapidly, enhancing the combustion quality and decreasing the $\mathrm{HC}$ emissions. For $\mathrm{NG}_{\mathrm{PH}}$ injection mode, on the one hand, the intermediates of hydrogen combustion, $\mathrm{O}$ and $\mathrm{OH}$ free radicals, can promote the oxidation of $\mathrm{HC}$ [57]. On the other hand, the favorable combustion characteristics of hydrogen such as low ignition energy and short quenching distance can lead to more $\mathrm{HC}$ emissions reduction [58]. The $\mathrm{HC}$ emissions of $\mathrm{NG}_{\mathrm{PD}}$ and $\mathrm{NG}_{\mathrm{PH}}$ modes decreased by $9.18 \%$ and $21.71 \%$ on average respectively than that of $\mathrm{NG}_{\mathrm{P}}$ mode. Therefore, an effective method for reducing $\mathrm{HC}$ emissions is through combined injection with hydrogen addition.

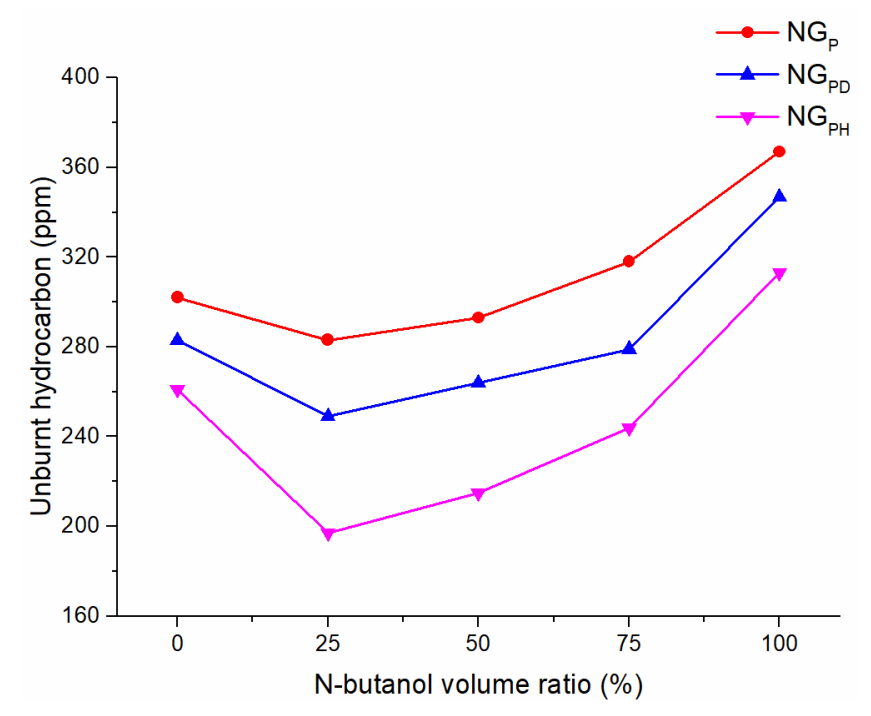

Fig. 13. HC emissions versus n-butanol volume ratios under different modes

\subsubsection{CO emission}

Fig. 14 shows that the $\mathrm{CO}$ emissions continuously reduce with the increasing $v_{N}$ under each injection mode. $\mathrm{CO}$ is an intermediate product formed by fuel incomplete combustion and its generated quantity is strongly associated with the oxygen concentration. Therefore, the oxygen lacking regions inside cylinder can be reduced due to the high oxygen content brought by n-butanol, which causes the decrease of $\mathrm{CO}$ emissions. Also the fast flame speed of nbutanol is conducive to reducing the $\mathrm{CO}$ emissions [59]. Fig. 14 also shows that the $\mathrm{CO}$ emissions of $\mathrm{NG}_{\mathrm{PD}}$ and 
$\mathrm{NG}_{\mathrm{PH}}$ combined modes are both lower than that of $\mathrm{NG}_{\mathrm{P}}$ mode under each $v_{N}$. The same as analyzing the combustion process, the favorable mixture concentration distribution inside cylinder formed by combined injection and the addition of hydrogen can curb the incomplete combustion. The $\mathrm{CO}$ emissions of NGPD and NGPH mode decreased by $19.22 \%$ and $32.63 \%$ on average respectively than that of $\mathrm{NG}_{\mathrm{P}}$ mode. Additionally, hydrogen has no carbon element, but this is not the main reason for such a sharp $\mathrm{CO}$ emissions decrement. Hence, the NGPD and NGPH combined modes have an obvious effect on the reduction of $\mathrm{CO}$ emissions.

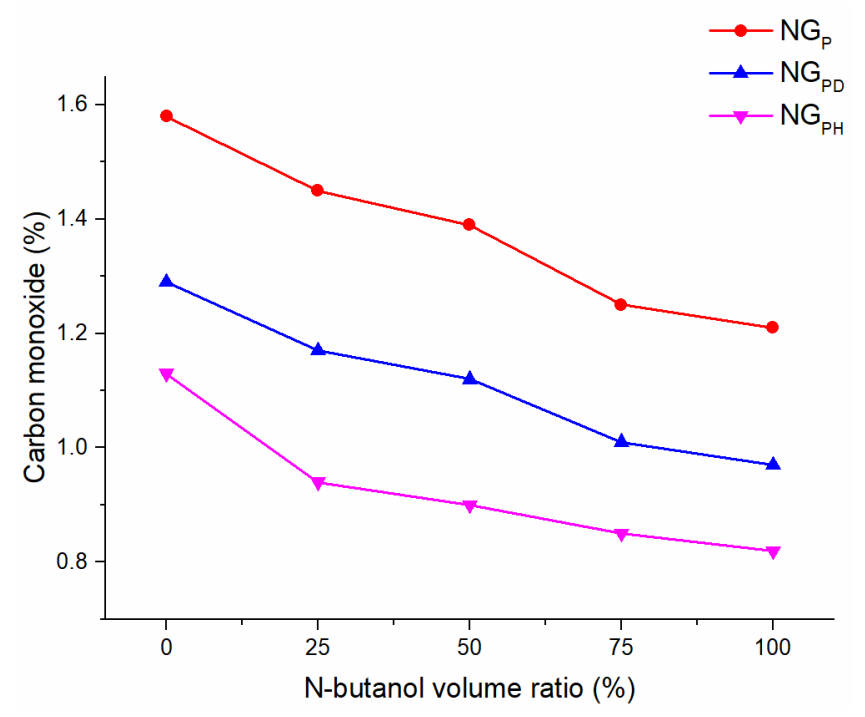

Fig. 14. CO emissions versus n-butanol volume ratios under different modes

\subsection{3 $\mathrm{NO}_{\mathrm{X}}$ emission}

As shown in Fig. 15, the $\mathrm{NO}_{\mathrm{X}}$ emissions initially rise and then fall with the increasing $v_{N}$ for all injection modes.

There is no nitrogen contained in the n-butanol blending gasoline fuel, so the generation of $\mathrm{NO}_{\mathrm{x}}$ emissions are primarily form the nitrogen in the air that involved in the combustion process inside cylinder. The formation mechanism of $\mathrm{NO}_{\mathrm{X}}$ is complicated and it is mainly affected by two factors, the temperature of combustion condition and the duration of staying at high temperature condition. As such, $\mathrm{NO}_{\mathrm{x}}$ emissions rise the maximum at $v_{N}=25 \%$ when the combustion quality of the mixed fuel performs the best and the peak heat release rate reaches the highest among all n-butanol volume ratios. Then as the $v_{N}$ continues to increase, the physico-chemical properties of nbutanol leads to the falling temperature inside cylinder and the shortened rapid combustion duration, which are 
unfavorable for the formation of $\mathrm{NO}_{\mathrm{X}}$, causing the decrease of $\mathrm{NO}_{\mathrm{X}}$ emissions. Although the oxygen content brought by n-butanol is still rising with the increase of $v_{N}$, the $\mathrm{NO}_{\mathrm{X}}$ emissions continuously decrease as a consequence of the low temperature.

On the basis of Fig. 9 above, the in-cylinder combustion temperature can be increased by combined injection as well as the addition of hydrogen, which is one of the main factors in generating $\mathrm{NO}_{\mathrm{x}}$ emissions. Hence, also as shown in Fig. 15, the $\mathrm{NO}_{\mathrm{X}}$ emissions of $\mathrm{NG}_{\mathrm{PD}}$ and $\mathrm{NG}_{\mathrm{PH}}$ combined modes are both higher than that of $\mathrm{NG}_{\mathrm{P}}$ mode under each $v_{N}$. The $\mathrm{NO}_{\mathrm{X}}$ emissions of $\mathrm{NG}_{\mathrm{PD}}$ and $\mathrm{NG}_{\mathrm{PH}}$ mode increased by $6.79 \%$ and $16.83 \%$ on average respectively than that of NGP mode. Hence, the addition of n-butanol above $v_{N}=50 \%$ can reduce the $\mathrm{NO}_{\mathrm{X}}$ emissions, however, the $\mathrm{NG}_{\mathrm{PD}}$ and $\mathrm{NG}_{\mathrm{PH}}$ combined modes will aggravate the $\mathrm{NO}_{\mathrm{X}}$ emissions.

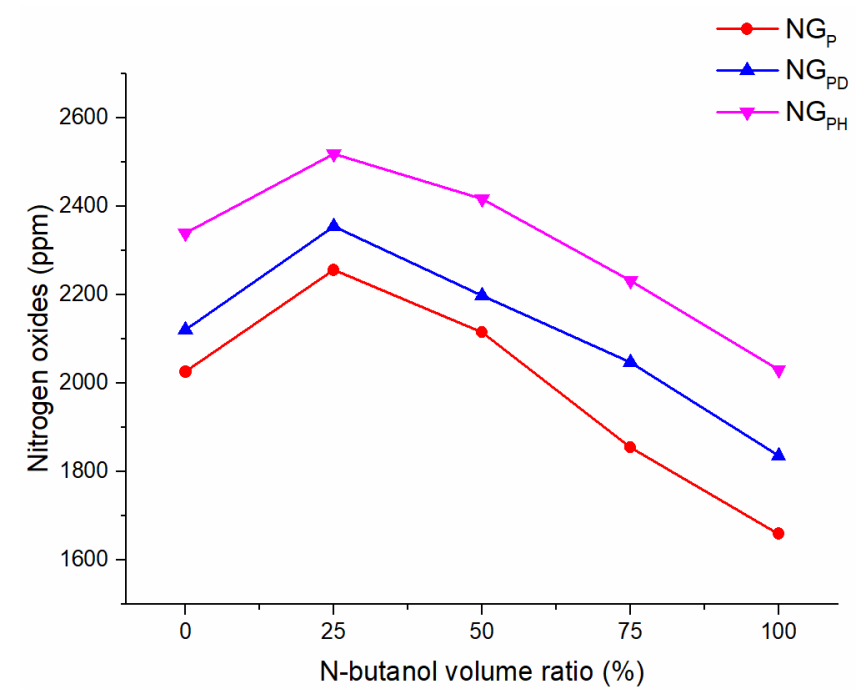

Fig. 15. $\mathrm{NO}_{\mathrm{X}}$ emissions versus n-butanol volume ratios under different modes

\section{Conclusions}

In this paper, the influence of the combination of combined injection and hydrogen supplement on combustion and emission characteristics of an n-butanol/gasoline blended SI engine has been compared and evaluated under the speed of $1200 \mathrm{r} / \mathrm{min}$ and $30 \mathrm{kPa}$ intake manifold absolute pressure. The performance of cylinder pressure, heat release rate, flame development duration, rapid combustion duration, cylinder temperature, BMEP, COV and $\mathrm{HC}, \mathrm{CO}$ and 
$\mathrm{NO}_{\mathrm{X}}$ emissions with five $\mathrm{n}$-butanol volume ratios under three injection modes are carried out. The main conclusions are summarized as follow:

1. Compared to NGP mode, the NGPD mode can achieve more reliable ignition and complete fuel combustion. As for $\mathrm{NG}_{\mathrm{PH}}$ mode, a local hydrogen-enriched area around the spark plug can be generated through HDI, which contributes to further improving the combustion performance.

2. The peak cylinder pressure of $\mathrm{NG}_{\mathrm{PD}}$ and $\mathrm{NG}_{\mathrm{PH}}$ mode is $5.58 \%$ and $11.63 \%$ higher than that of $\mathrm{NG}_{\mathrm{P}}$ mode on average, respectively. Also the combined injection modes concentrate the process of heat release, shorten the flame development duration and rapid combustion duration, increase the peak cylinder temperature and BMEP.

3. The effect rules of $v_{N}$ on combustion and emission performances for $\mathrm{NG}_{\mathrm{P}}$ mode are consistent with those of the NGPD and NGPH combined modes. When the $v_{N}=25 \%$, the small amount of n-butanol can increase the oxygen content and laminar flame speed of mixed fuel and improve the combustion performance. At $v_{N}=50 \%$, these advantageous physico-chemical properties can still promote a slight increase. But as the $v_{N}$ continues to increase, the disadvantage of poor evaporation and atomization performance of n-butanol gradually reveal out, resulting in a worse combustion quality.

4. The combined injection modes can significantly improve the combustion stability, while the COV can be further controlled below $1.0 \%$ by hydrogen addition. For another, the COV obtains the minimum at $v_{N}=25 \%$ under all injection modes.

5. In terms of emissions, the $\mathrm{HC}$ and $\mathrm{CO}$ emissions of $\mathrm{NG}_{\mathrm{PD}}$ and $\mathrm{NG}_{\mathrm{PH}}$ combined modes are both significantly less than those of $\mathrm{NG}_{\mathrm{P}}$ mode, and the $\mathrm{NG}_{\mathrm{PH}}$ mode has the lowest level among three injection modes. However, the $\mathrm{NG}_{\mathrm{PD}}$ and $\mathrm{NG}_{\mathrm{PH}}$ mode obviously increase the $\mathrm{NO}_{\mathrm{X}}$ emissions. For another, under each injection mode with the increasing $v_{N}$, the $\mathrm{HC}$ emissions initially fall and then rise, obtaining the minimum at $v_{N}=25 \%$. The $\mathrm{CO}$ emissions continuously reduce. The $\mathrm{NO}_{\mathrm{X}}$ emissions initially rise and then fall, 
reaching the maximum at $v_{N}=25 \%$.

6. Among all the test conditions, the $\mathrm{NG}_{\mathrm{PH}}$ mode with $25 \% v_{N}$ obtains the best combustion quality. Its peak cylinder pressure, peak heat release rate, peak cylinder temperature and BMEP reach the maximum values, and the $\mathrm{COV}$ and flame development duration obtain the minimum values. Also the $\mathrm{HC}$ and $\mathrm{CO}$ emissions

level are reduced but the $\mathrm{NO}_{\mathrm{x}}$ emissions are at most.

\section{Acknowledgements}

This study was funded by the National Natural Science Foundation of China (Grant No. 51276079), the State Scholarship Fund (File No.201906170179) and the Ph.D. Interdisciplinary Research Programs Foundation of Jilin University (Project No. 10183201825).

\section{References}

[1] S.P. Chincholkara, J.G. Suryawanshib, Gasoline direct injection: an efficient technology, Energy Procedia 90 (2016) 666-672.

[2] G. Saliba, R. Saleh, Y. Zhao, A.A. Presto, A.T. Larnbe, et al., Comparison of gasoline direct-injection (GDI) and port fuel injection (PFI) vehicle emissions: emission certification standards, cold-start, secondary organic aerosol formation potential, and potential climate impacts, Environmental Science \& Technology 51 (2017) 6542-6552.

[3] Y. Han, S. Hu, M. Tan, Y. Xu, J. Tian, et al., Experimental study of the effect of gasoline components on fuel economy, combustion and emissions in GDI engine, Fuel 216 (2018) 371-380.

[4] P.G. Aleiferis, Z.R. van Romunde, An analysis of spray development with iso-octane, n-pentane, gasoline, ethanol and n-butanol from a multi-hole injector under hot fuel conditions, Fuel 105 (2013) 143-168.

[5] R. Zhu, J. Hu, X. Bao, L. He, Y. Lai, et al., Tailpipe emissions from gasoline direct injection (GDI) and port fuel injection (PFI) vehicles at both low and high ambient temperatures, Environmental Pollution 216 (2016) 223-234.

[6] A. Viggiano, V. Magi, A comprehensive investigation on the emissions of ethanol HCCI engines, Applied Energy 93 (2012) $277-287$.

[7] A.V.S. Oliveira, G.H.M. Alegre, R.G. Santos, A comprehensive experimental study on nucleate boiling in gasoline and gasoline-ethanol blends, Experimental Thermal and Fluid Science 88 (2017) 134-144.

[8] C. Jin, M. Yao, H. Liu, C.F. Lee, J. Ji, Progress in the production and application of n-butanol as a biofuel, Renewable and Sustainable Energy Reviews 15 (2011) 4080-4106

[9] T. Wallner, S.A. Miers, S. McConnell, A comparison of ethanol and butanol as oxygenates using a direct-injection, spark-ignition engine, Journal of Engineering for Gas Turbines and Power 131 (2009) 1-9.

[10] J.L.S. Fagundez, D. Golke, M.E.S. Martins, N.P.G. Salau, An investigation on performance and combustion characteristics of pure n-butanol and a blend of n-butanol/ethanol as fuels in a spark ignition engine, Energy 176 (2019) 521-530.

[11] H. Wei, D. Feng, M. Pan, J. Pan, X. Rao, et al., Experimental investigation on the knocking combustion characteristics of n-butanol gasoline blends in a DISI engine, Applied Energy 175 (2016) 346-355.

[12] Z. Tian, X. Zhen, Y. Wang, D. Liu, X. Li, Combustion and emission characteristics of n-butanol-gasoline blends in SI direct injection gasoline engine, Renewable Energy 146 (2020) 267-279.

[13] S. Szwaja, J.D. Naber, Combustion of n-butanol in a spark-ignition IC engine, Fuel 89 (2010) 1573-1582.

[14] A. Elfasakhany, Experimental study on emissions and performance of an internal combustion engine fueled with gasoline and gasoline/n-butanol blends, Energy Conversion and Management 88 (2014) 277-283.

[15] Z. Chen, Y. Zhang, X. Wei, Q. Zhang, Z. Wu, et al., Thermodynamic process and performance of high n-butanol/gasoline blends fired in a GDI production engine running wide-open throttle (WOT), Energy Conversion and Management 152 (2017) 57-64.

[16] Z. Chen, F. Yang, S. Xue, Z. Wu, J. Liu, Impact of higher n-butanol addition on combustion and performance of GDI engine in stoichiometric combustion, Energy Conversion and Management 106 (2015) 385-392.

[17] B. He, X. Chen, C. Lin, H. Zhao, Combustion characteristics of a gasoline engine with independent intake port injection and direct injection systems for nbutanol and gasoline, Energy Conversion and Management 124 (2016) 556-565.

[18] D. Feng, H. Wei, M. Pan, L. Zhou, J. Hua, Combustion performance of dual-injection using n-butanol direct-injection and gasoline port fuel-injection in a SI engine, Energy 160 (2018) 573-581. 
[19] T. Venugopal, A. Ramesh, Experimental studies on the effect of injection timing in a SI engine using dual injection of n-butanol and gasoline in the intake port, Fuel 115 (2014) 295-305.

[20] A. Irimescu, S.S. Merola, C. Tornatore, G. Valentino, Effect of coolant temperature on air-fuel mixture formation and combustion in an optical direct injection spark ignition engine fueled with gasoline and butanol, Journal of the Energy Institute 90 (2017) 452-465.

[21] P.G. Aleiferis, J.S. Pereira, D. Richardson, Characterisation of flame development with ethanol, butanol, iso-octane, gasoline and methane in a direct-injection spark-ignition engine, Fuel 109 (2013) 256-278.

[22] Y. Karagoz, N. Yuca, T. Sandalc1, A.S. Dalkılic, Effect of hydrogen and oxygen addition as a mixture on emissions and performance characteristics of a gasoline engine, International Journal of Hydrogen Energy 40 (2015) 8750-8760.

[23] H.L. Yip, A. Srna, A.C.Y. Yuen, S. Kook, R.A. Taylor, et al., A review of hydrogen direct injection for internal combustion engines: towards carbon-free combustion, Applied Sciences 9 (2019) 4842-4871.

[24] S. Verhelst, P. Maesschalck, N. Rombaut, R. Sierens, Increasing the power output of hydrogen internal combustion engines by means of supercharging and exhaust gas recirculation, International Journal of Hydrogen Energy 34 (2009) 4406-4412.

[25] A.M. Pourkhesalian, A.H. Shamekhi, F. Salimi, Alternative fuel and gasoline in an SI engine: A comparative study of performance and emissions characteristics, Fuel 89 (2010) 1056-1063.

[26] U. Eberle, M. Felderhoff, F. Schuth, Chemical and physical solutions for hydrogen storage, Angewandte Chemie International Edition 48 (2009) 6608-6630.

[27] C. Sopena, P.M. Dieguez, D. Sainz, J.C. Urroz, E. Guelbenzu, et al., Conversion of a commercial spark ignition engine to run on hydrogen: Performance comparison using hydrogen and gasoline, International Journal of Hydrogen Energy 35 (2010) 1420-1429.

[28] R. Niu, X. Yu, Y. Du, H. Xie, H. Wu, et al., Effect of hydrogen proportion on lean burn performance of a dual fuel SI engine using hydrogen direct-injection Fuel $186(2016) 792-799$

[29] A. Mohammadi, M. Shioji, Y. Nakai, W. Ishikura, E. Tabo, Performance and combustion characteristics of a direct injection SI hydrogen engine, International Journal of Hydrogen Energy 32 (2007) 296 - 304.

[30] C. Ji, S. Wang, B. Zhang, Performance of a hybrid hydrogen-gasoline engine under various operating conditions, Applied Energy 97 (2012) $584-589$.

[31] T. Su, C. Ji, S. Wang, L. Shi, J. Yang, et al., Investigation on performance of a hydrogen-gasoline rotary engine at part load and lean conditions, Applied Energy 205 (2017) 683-691.

[32] C. Ji, S. Wang, Experimental study on combustion and emissions performance of a hybrid hydrogen-gasoline engine at lean burn limits, International Journal of Hydrogen Energy 35 (2010) 1453-1462.

[33] J.H. Zhou, C.S. Cheung, W.Z. Zhao, C.W. Leung, Diesel-hydrogen dual-fuel combustion and its impact on unregulated gaseous emissions and particulate emissions under different engine loads and engine speeds, Energy 94 (2016) 110-123.

[34] L. Zhu, Z.Y. He, Z. Xu, Z. Gao, A. Li, et al., Improving cold start, combustion and emission characteristics of a lean burn spark ignition natural gas engine with multi-point hydrogen injection, Applied Thermal Engineering 121 (2017) 83-89.

[35] W. Shi, X. Yu, Efficiency and Emissions of spark ignition engine using hydrogen and gasoline mixtures, Advanced Materials Research 1070 (2015) 1835 1839.

[36] R.A. Bakar, M.K. Mohammed, M.M. Rahman, Numerical study on the performance characteristics of hydrogen fueled port injection internal combustion engine, American J. of Engineering and Applied Sciences 2 (2009) 407-415.

[37] J. Duan, F. Liu, B. Sun, Backfire control and power enhancement of a hydrogen internal combustion engine, International Journal of Hydrogen Energy 39 (2014) 4581-4589.

[38] T. Su, C. Ji, S. Wang, X. Cong, L. Shi, Improving the lean performance of an n-butanol rotary engine by hydrogen enrichment, Energy Conversion and Management 157 (2018) 96-102.

[39] J. Yang, C. Ji, A comparative study on performance of the rotary engine fueled hydrogen/gasoline and hydrogen/n-butanol, International Journal of Hydrogen Energy 43 (2018) 22669-22675.

[40] E. Sukjit, J.M. Herreros, K.D. Dearnm A. Tsolakis, K. Theinnoi, Effect of hydrogen on butanol-biodiesel blends in compression ignition engines, International Journal of Hydrogen Energy 38 (2013) 1624-1635.

[41] S. Raviteja, G.N. Kumar, Effect of hydrogen addition on the performance and emission parameters of an SI engine fueled with butanol blends at stoichiometric conditions, International Journal of Hydrogen Energy 40 (2015) 9563-9569.

[42] Y. Du, X. Yu, J. Wang, H. Wu, W. Dong, et al., Research on combustion and emission characteristics of a lean burn gasoline engine with hydrogen directinjection. International Journal of Hydrogen Energy 41 (2016) 3240-3248.

[43] Z. Shang, X. Yu, W. Shi, S. Huang, G. Li, et al., Numerical research on effect of hydrogen blending fractions on idling performance of an n-butanol ignition engine with hydrogen direct injection, Fuel 258 (2019) 1-12.

[44] F. Meng, X. Yu, L. He, Y. Liu, Y. Wang, Study on combustion and emission characteristics of a n-butanol engine with hydrogen direct injection under lean burn conditions, International Journal of Hydrogen Energy 43 (2018) 7550-7561.

[45] Y. Wang, X. Yu, Y. Ding, Y. Du, Z. Chen, et al., Experimental comparative study on combustion and particle emission of n-butanol and gasoline adopting different injection approaches in a spark engine equipped with dual-injection system, Fuel 211 (2018) 837-849.

[46] X. Yu, Z. Guo, L. He, W. Dong, P. Sun, et al., Effect of gasoline/n-butanol blends on gaseous and particle emissions from an SI direct injection engine, Fuel 229 (2018) $1-10$

[47] F. He, S. Li, X. Yu, Y. Du, X. Zuo, et al., Comparison study and synthetic evaluation of combined injection in a spark ignition engine with hydrogen-blended at lean burn condition, Energy 157 (2018) 1053-1062.

[48] X. Yu, Y. Du, P. Sun, L. Liu, H. Wu, et al., Effects of hydrogen direct injection strategy on characteristics of lean-burn hydrogen-gasoline engines, Fuel 208 (2017) 602-611.

[49] X. Yu, X. Zuo, H. Wu, Y. Du, Y. Sun, et al., Study on combustion and emission characteristics of a combined injection engine with hydrogen direct injection, Energy\&fuels 31 (2017) 5554-5560.

[50] I.M. Yusri, R. Mamat, G. Najafi, A. Razman, O.I. Awad, et al., Alcohol based automotive fuels from first four alcohol family in compression and spark ignition engine: A review on engine performance and exhaust emissions, Renewable and Sustainable Energy Reviews 77 (2017) 169-181.

[51] T. Tahtouh, F. Halter, C. Mounaïm-Rousselle, E. Samson, Experimental investigation of the initial stages of flame propagation in a spark-ignition engine: effects of fuel, hydrogen addition and nitrogen dilution, International Journal of Engines 1 (2010) 1451-1469.

[52] C. Guan, C.S. Cheung, X. Li, Z. Huang, Effects of oxygenated fuels on the particle-phase compounds emitted from a diesel engine, Atmospheric Pollution Research 8 (2017) 209-220.

[53] T. Wallner, A. Lckes, K. Lawyer, Analytical assessment of C2-C8 alcohols as spark-ignition engine fuels, Proceedings of the FISITA 2012 World Automotive Congress 191 (2013) 15-26.

[54] Y. Li, L. Meng, K. Nithyanandan, T.H. Lee, Y. Lin, et al., Combustion, performance and emissions characteristics of a spark-ignition engine fueled with isopropanol-n-butanol-ethanol and gasoline blends, Fuel 184 (2016) 864-872.

[55] X. Gu, Z. Huang, S. Wu, Q. Li, Laminar burning velocities and flame instabilities of butanol isomers-air mixtures, Combustion and Flame 157 (2010) 2318 2325.

[56] S. Szwaj, J.D. Naber, Combustion of n-butanol in a spark-ignition IC engine, Fuel 89 (2010) 1573-1582

[57] J. Wang, Z. Huang, C. Tang, H. Miao, X. Wang, Numerical study of the effect of hydrogen addition on methane-air mixtures combustion, International Journal of Hydrogen Energy 34 (2009) 1084-1096.

[58] C. Ji, S. Wang, Experimental study on combustion and emissions performance of a hybrid hydrogen-gasoline engine at lean burn limits, International Journal of Hydrogen Energy 35 (2010) 1453-1462.

[59] M.N.A.M. Yusoff, NW.M. Zulkifli, H.H. Masjuki, M.H. Harith, A.Z. Syahir, et al., Performance and emission characteristics of a spark ignition engine fuelled with butanol isomer-gasoline blends, Transportation Research Part D: Transport and Environment 57 (2017) 23-38 